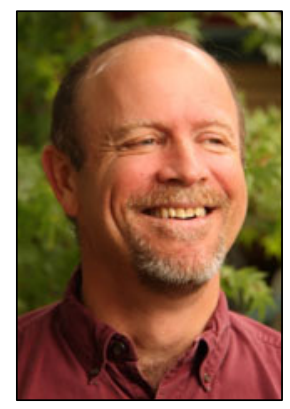

\author{
VieWs FROM THE FoOd SYSTEM FrontIER \\ Emerging trends, dilemmas, and opportunities in the changing global food system \\ JOSEPH MCINTYRE
}

\title{
The emergence of a field
}

Published online 22 June 2012

Citation: McIntyre, J. (2012). The emergence of a field. Journal of Agriculture, Food Systems, and Community Development, 2(3), 9-10. http://dx.doi.org/10.5304/jafscd.2012.023.018

Copyright (C) 2012 by New Leaf Associates, Inc.

J anuary 24, 2012, may not go down as a particularly noteworthy day overall, but for the growing sustainable food systems field it marked an important milestone. On this day, the Community Food Security Coalition's venerable COMFOOD listserv (http://www.foodsecurity.org/list.html) announced it was separating job announcements that were routinely posted on the list into a new listserv, COMFOOD JOBS.

The emergence of a dedicated vehicle for posting jobs in sustainable food systems is a coming-of-age event for our field. In the few short

Joseph Mclntyre is president of Ag Innovations Network, a California-based nongovernmental organization that focuses exclusively on developing and facilitating collaborations between interests in the food system to promote change in practices and policies. Trained as both an economist and an organization development professional, he works with food system leaders on complex change initiatives.

This is part of an ongoing series of columns by Mr. Mclntyre on emerging trends, dilemmas, and opportunities in the changing global food system. He can be reached at joseph@aginnovations.org. months since the listserv came online, over 400 jobs and related posts have gone on the list. The diversity of job titles, geographies, and education and experience requirements is extraordinary. Consider that in just June of this year job announcements have been made for positions ranging from a driver for a mobile livestock program in Taos, New Mexico, to a healthy food access expert in California, to a business manager for a New York-based food systems consulting firm. Farms, businesses, and community-based organizations are looking for everything from interns to experienced experts in creating the new food system.

The emergence of a new, dedicated field focused on the twin challenges of growing food in more sustainable ways as well as addressing the urgent health and food access needs of urban populations is requiring a new mix of skills and expertise. These jobs, taken together, call for a background that is part agroecology, part marketing, part community development, and all entrepreneurial.

Our university partners, as described in this issue of JAFSCD, are working hard to meet the 
demands of these new positions as well as provide the underlying research that will help fuel innovation in the field. But it's not an easy task. The emergence of a new field, and some would argue a new paradigm, is never easy on the educational system.

One of the core challenges and frustrations practitioners in the field experience is trying to fit a fundamentally holistic and interdisciplinary set of research and practical questions into the traditional academic boundaries and even into the scientific method.

Just a few weeks ago, I had a vivid experience of this while facilitating a workshop on cover cropping in Midwest commodity agriculture. It turns out there is a huge opportunity to increase soil health, reduce water pollution, and provide additional habitat for a variety of species through the relatively simple practice of planting cover crops on fields that are traditionally left bare. However, champions for this practice consistently reported that their academic partners were well behind them in terms of providing research to support what they see with their eyes on their fields or extension support to help other farmers experiment with these new practices. In particular, they mentioned the challenge of studying highly diverse systems with multiple varieties of cover crops being grown simultaneously. Situations like this challenge traditional research methodologies. As I thought back to my own training as an economist, where our goal was to try to understand the economic system under conditions of ceteris paribus (with other things the same) by allowing only one variable to change, I could see that that method, which is similar in many ways to traditional science approaches, was hopelessly oversimplified for understanding these living systems.

The good news is that we have learned how to do interdisciplinary science, and good research is taking place. I am heartened by the work being produced at land-grant schools like the University of California-Davis in its Agricultural Sustainability
Institute, at private schools such as Tufts University in its Agriculture, Food, and Environment program, and at dozens of other institutions small and large that are reconfiguring their courses and, more importantly, their objectives to meet this new field head on.

That said, it can still be a frustrating and slow experience working with our academic partners. Caught as they are in their own institutional imperatives, ranging from tenure requirements to demands for publishing and the general disinvestment that has been occurring in American public education for the past 20 years, universities and colleges find themselves with less flexibility than would be ideal to rise up to this new opportunity. I would describe this as a "tight system," one that that is loaded with potential and talent, but is often shackled by creativitydampening rules and protocols. I believe one of the keys to moving this field forward more quickly is to re-envision the relationship between science and community. The growing field of citizen science and crowd-sourced information is opening new opportunities for both communities and academia. Many of the key research questions — and almost all of the job opportunities — in the new sustainable food system are to be found on small farms, urban rooftop gardens, new food distribution hubs, and in the plethora of experimentation that is already happening on the ground. These new settings call for new approaches. What we need is a vigorous partnership between civil society, the community at large, and academia to identify and answer together key questions that will enable our field to grow. From basic agronomic issues, to questions of how best to structure our new food businesses for economic viability, there is no shortage of work to do.

Our field is growing. The job postings highlight this. The question now is can we effectively train people for a new field that is being defined even as it forms. I believe we can, if we can lower the Ivory Tower just a bit. 